ллавный путь длиною в жизнь: к 70-летию кафедры дерматовенерологии Южно-Уральского государственного медицинского университета

\author{
О.Р. Зиганшин, О.В. Лысенко, Ю.Н. Ковалев, О.И. Летяева
}

ГБОУ ВПО «Южно-Уральский государственный медицинский университет» Минздрава России 454092, г. Челябинск, ул. Воровского, 64

В статье изложен материал, повествующий об образовании, становлении и развитии касредры кожных и венерических болезней Челябинского медицинского института, в настоящее время именуемой кафедрой дерматовенерологии Южно-Уральского государственного медицинского университета. Представлены архивные сротодокументы и современные фротограсрии.

Ключевые слова: Челябинск, кафедра, дерматовенерология, научные исследования.

Контактная информация: olga_lisenko@bk.ru. Вестник дерматологии и венерологии 2014; (5): 117_121.

\title{
A lifelong path of glory: on the 70th anniversary of the Chair of Dermatovenerology, South Ural State Medical University
}

\author{
O.R. Ziganshin, O.V. Lysenko, Yu.N. Kovalev, O.I. Letyayeva
}

South Ural State Medical University (State Budgetary Educational Institution for Higher Professional Education), Ministry of Healthcare of the Russian Federation Vorovskogo, 64, Chelyabinsk, 454092, Russia

A lifelong path of glory: on the 70th anniversary of the Chair of Dermatovenerology, South Ural State Medical University Key words: Chelyabinsk, chair of dermatovenerology. 
История кафедры дерматовенерологии, как и всего Челябинского медицинского института, начинается в 1944 г. и является своеобразным продолжением истории Киевского медицинского института, находившегося в эвакуации в Челябинске во время Великой Отечественной войны. Тогда после освобождения Киева часть преподавателей вуза вернулась на родину, а часть осталась в Челябинске, так как решением правительства в городе был создан медицинский институт. По этой причине, в отличие от других молодых вузов, к преподаванию сразу приступили высокопрофессиональные сотрудники, имеющие большой опыт и преподавательской, и научной деятельности. Так, ректором института и одновременно заведующим кафедрой кожных и венерических болезней стал профессор Александр Николаевич Федоровский (1890-1964) - опытный организатор, педагог и прекрасный клиницист. Совместно с преподавателями А.А. Брябриной, С.Г. Колбиным и В.Н. Манохиным в трудных условиях военного времени и послевоенных лет, несмотря на голод и разруху, ему удалось организовать клинику института на базе военного госпиталя, а позднее - городского кожного диспансера, последипломное образование в фрорме клинической ординатуры и научное общество дерматологов и венерологов Челябинска. Тогда научные интересы кафедры были сфокусированы на борьбе с венерическими и заразными кожными заболеваниями. На эту тему были опубликованы 75 научных работ.

Вторым заведующим стал ученик известного дерматолога П.С. Григорьева доцент Константин Петрович Кочетов (1903-1978), проработавший на кафедре с 1952 по 1965 г. В то время кафедра насчитывала всего двух преподавателей и опубликовала только 23 работы.

Значительно изменило историю кафедры избрание на заведование в 1965 г. кандидата медицинских наук, капитана первого ранга медицинской службы Иосифа Израилевича Ильина (1921-1994). И.И. Ильин закончил адъюнктуру (аспирантуру) на кафедре кожных и венерических болезней Военно-морской медицинской академии и в 1950 г. защитил кандидатскую, а в 1966 г., сразу после начала заведования, - докторскую диссертацию на тему «Актуальные проблемы негонококковых уретритов венерического происхождения». В 1967 г. ему было присвоено звание профессора. С началом руководства кафедрой И.И. Ильина педагогическая и научная активность сотрудников значительно оживилась: была улучшена материальная база, разработаны современные на тот момент времени методы наглядного сопровождения учебного процесса, защитили кандидатские диссертации преподаватели кафедры В.А. Пасечник и П.Ф. Тряпичников, увеличилось число преподавателей, ряды которых пополнились учениками И.И. Ильина.

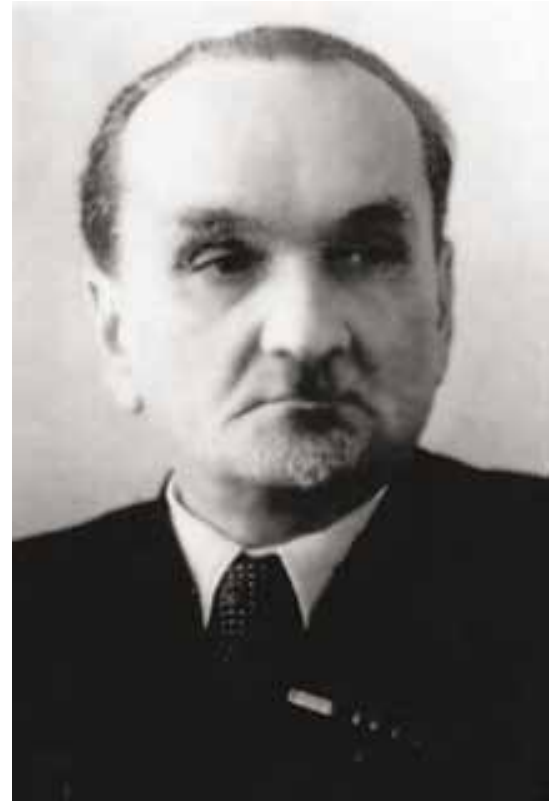

Заведующий кафедрой кожных и венерических болезней профрессор А.Н. Федоровский (1944-1952)

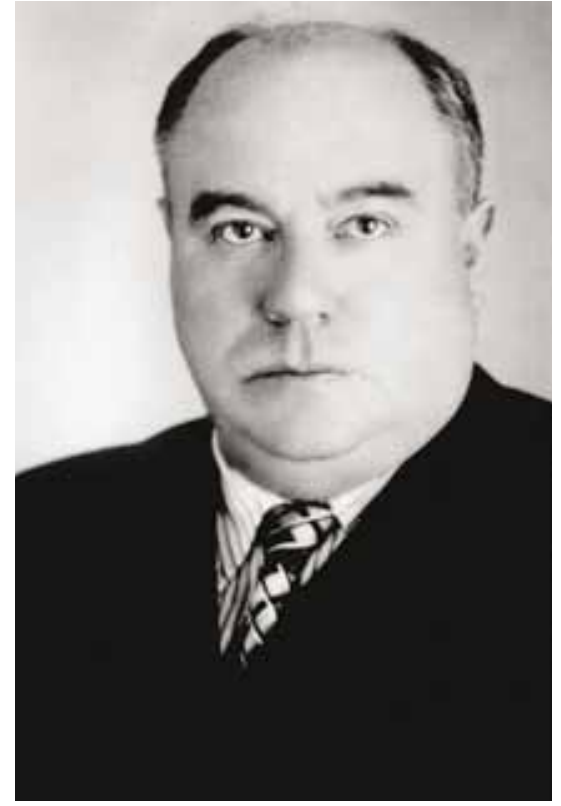

Заведующий кафедрой доцент К.П. Кочетов (19521965)

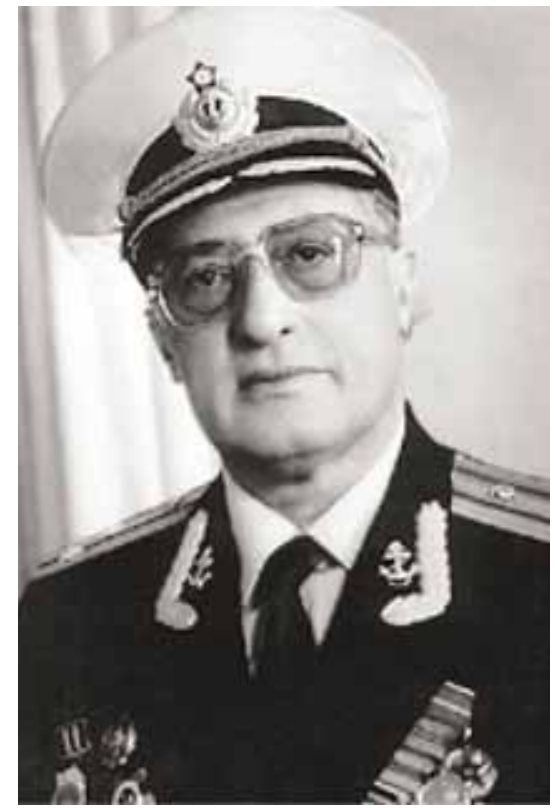

Заведующий кафедрой дерматовенерологии профрессор И.И. Ильин (1965-1991) 
Навсегда пропитавшись питерской атмосферой истинной интеллигентности и интеллектуальности, Иосиф Израилевич был при этом человеком весьма требовательным, блестящим клиницистом, отлично владел организацией научной работы и навыками педагогического мастерства. Его лекции были одновременно высокоинформативны и артистичны, содержали самые современные данные по дисциплине и информацию из истории мировой культуры, литературы, живописи. Учили становиться профессионалами и настоящими людьми.

Кафедра наладила тесные научные связи с рядом ведущих учреждений: Центральным кожно-венерологическим институтом России, Институтом эпидемиологии имени Н.Ф. Гамалеи, Институтом ревматологии РАМН МЗ России, Медицинской академией Варшавы, Украинским кожно-венерологическим НИИ, Свердловским НИИ, многими ведущими кафедрами дерматовенерологии СССР.

Основными научными проблемами, которые разрабатывались И.И. Ильиным и его учениками, были вопросы совершенствования методик лечения сифилиса, вопросы негонококковых и гонококковых воспалительных заболеваний мочеполовых органов и их осложнений. И.И. Ильин и его ученики одними из первых в отечественной венерологии указали на роль хламидийной инфекции в урогенитальной патологии и развитии болезни Рейтера, придавая особое значение эпидемиологии негонококковых уретритов, в то время когда само существование негонококковых уретритов ставилось под сомнение.

Сотрудники кафедры непрерывно совершенствовали учебно-педагогический процесс, используя на лекциях и практических занятиях наборы восковых муляжей, вывезенных из Киева в годы войны преподавателями Киевского медицинского института, сохраненных и реставрированных в Челябинске, организовав библиотеку рентгенограмм, демонстрируя на лекциях и практических занятиях созданную И.И. Ильиным огромную коллекцию цветных слайдов по всем изучаемым вопросам.

Профрессор И.И. Ильин - автор 325 работ, четырех монографий, в том числе монографии «Негонококковые уретриты у мужчин», выдержавшей три издания в издательстве «Медицина», соавтор двух изданий учебника по дерматовенерологии для студентов, монотематических сборников и т. д. Под его руководством были защищены три докторские и 13 кандидатских диссертаций, но и после его смерти еще ряд лет ученики созданной им школы заканчивали исследования, инициированные Иосифом Израилевичем. Профессор И.И. Ильин являлся членом редакционного совета журнала «Вестник дерматологии и венерологии», членом научного совета по дерматологии и венерологии АМН СССР, был избран почетным членом Всероссийского общества дерматологов и венерологов.
Являясь участником Великой Отечественной войны, И.И. Ильин был награжден орденом Отечественной войны II степени, двумя орденами Красной звезды, двумя медалями «За боевые заслуги» и 14 другими медалями.

В 1991 г. Иосиф Израилевич передал кафедру своему ученику, профессору Юрию Николаевичу Ковалеву, и перешел на должность профессора. Ю.Н. Ковалев, закончивший клиническую ординатуру и аспирантуру на кафедре кожных и венерических болезней Челябинского государственного медицинского института, в 1971 г. защитил кандидатскую, а в 1988 г. - докторскую диссертацию на тему «Роль иммунных нарушений в патогенезе, клиника и патогенетическая терапия болезни Рейтера». Согласно этой, близкой ему теме, Ю.Н. Ковалев развивал основное направление научной деятельности, посвятив ее изучению диагностики и лечения болезни Рейтера. Им были разработаны эффективные методики лечения урогенитальных инфекций и их осложнений у мужчин, широко использовавшиеся в практической медицине. К 2014 г. опубликовано 286 научных работ, он является соавтором трех монографий, 13 методических рекомендаций, учебника по дерматовенерологии для студентов медицинских институтов и врачей, четырех двухтомных руководств для врачей «Кожные и венерические болезни», двухтомного руководства для врачей «Клиническая дерматовенерология», двух изданий национального руководства «Дерматовенерология». Участник ВДНХ СССР. Имеет три изобретения. Подготовил двух докторов медицинских наук и 10 кандидатов и в настоящее время работает профрессором кафедры, также передав руководство одному из своих последователей.

С 2011 г. кафедрой дерматовенерологии заведует доктор медицинских наук Олег Раисович Зиганшин. После окончания лечебного факультета Челябинского государственного медицинского института в 1993 г. О.Р. Зиганшин проходил обучение в клинической интернатуре и аспирантуре кафедры кожных и венерических болезней Челябинского государственного медицинского института, в 1997 г. защитил кандидатскую диссертацию. Докторская диссертация, защищенная в 2003 г., посвящалась теме: «Сравнительная клинико-иммунологическая характеристика и оценка эффективности цитокиновой терапии воспалительных заболеваний половой сферы у мужчин». Автор 198 научных работ в российских и зарубежных изданиях, девяти методических пособий с грифом УМО, активный участник российских и международных конгрессов и съездов, О.Р. Зиганшин имеет патент РФ по диагностике хронического простатита, является автором монографии «Механизмы антибактериальной резистентности репродуктивных органов мужчин». 


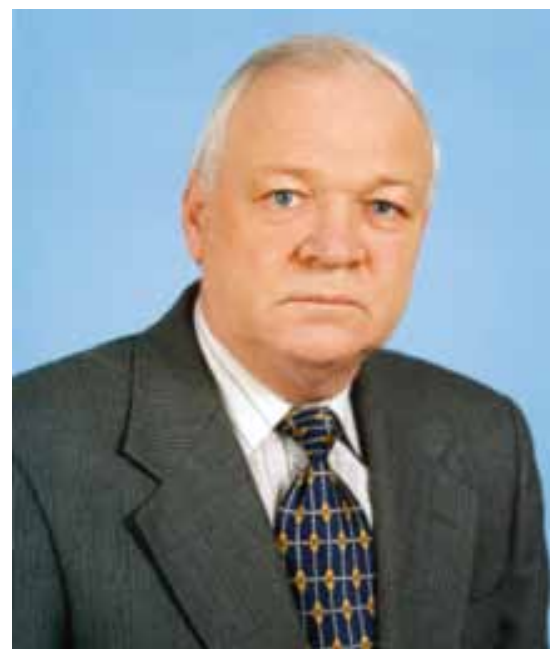

Заведующий кафедрой профессор Ю.Н. Ковалев (1991-2011)

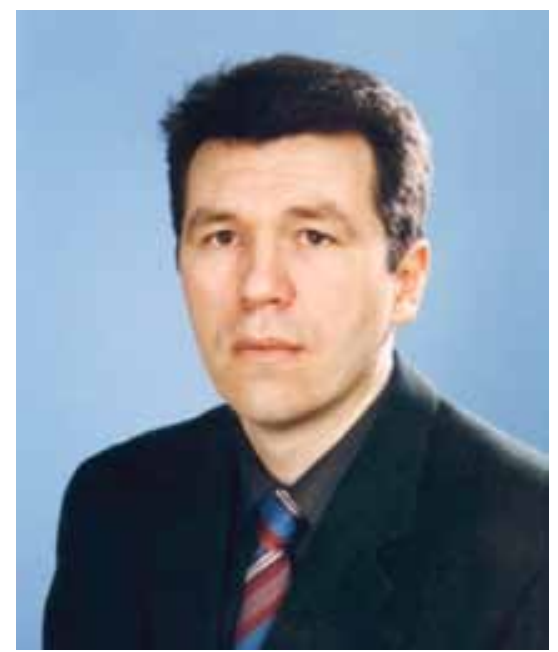

Заведующий кафедрой дерматовенерологии д.М.н. О.Р. Зиганшин

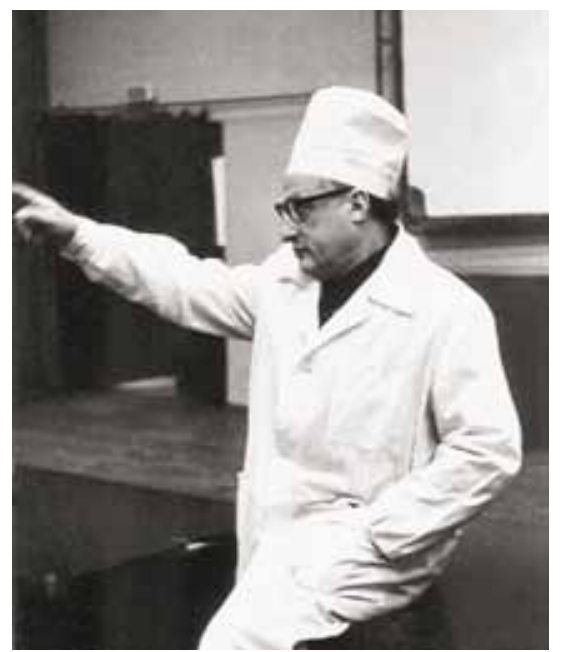

Профессор И.И. Ильин на лекции

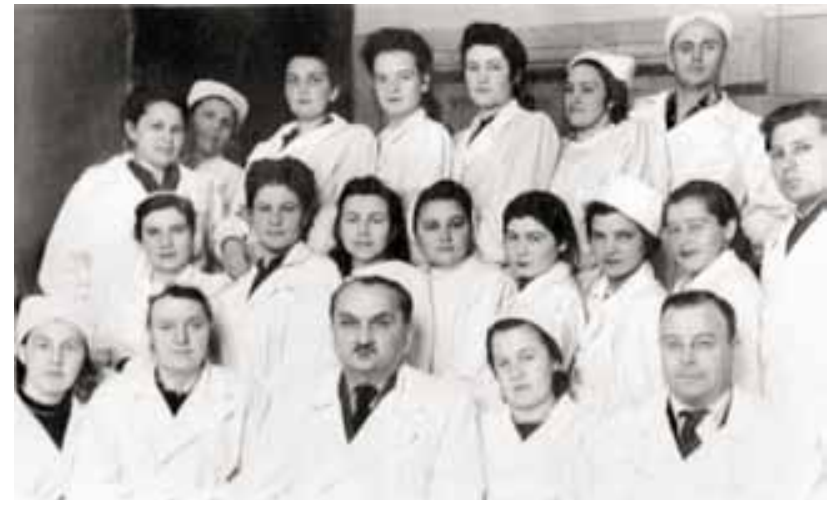

Первые преподаватели кафредры кожных и венерических болезней с ординаторами (1945 г.)

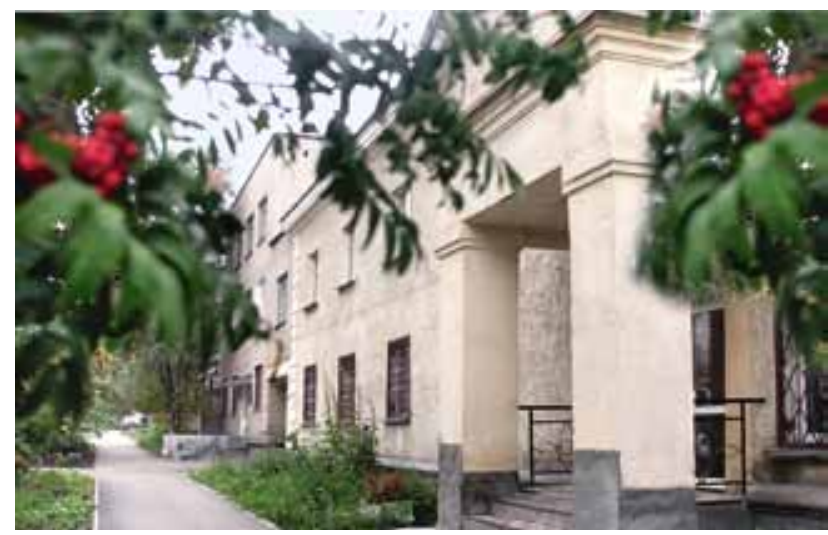

Главный учебный корпус кафедры дерматовенерологии ЮУГМУ (2013 г.)

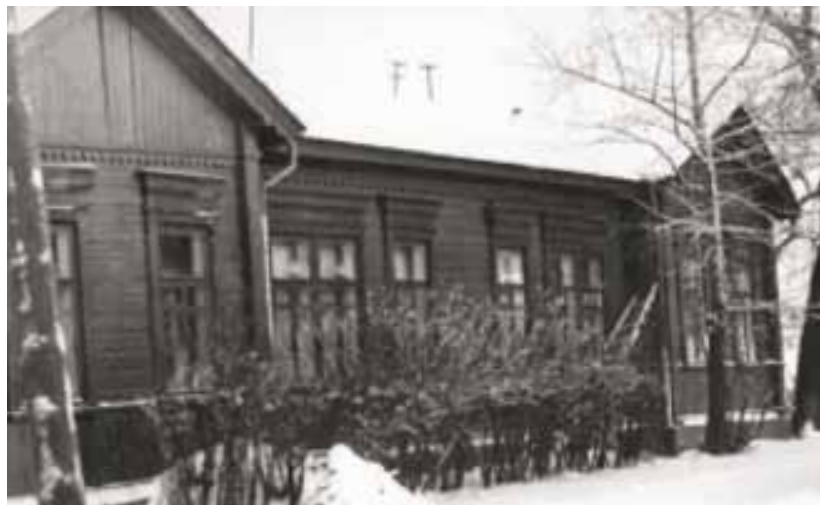

Первое помещение кафедры (1945 г.)

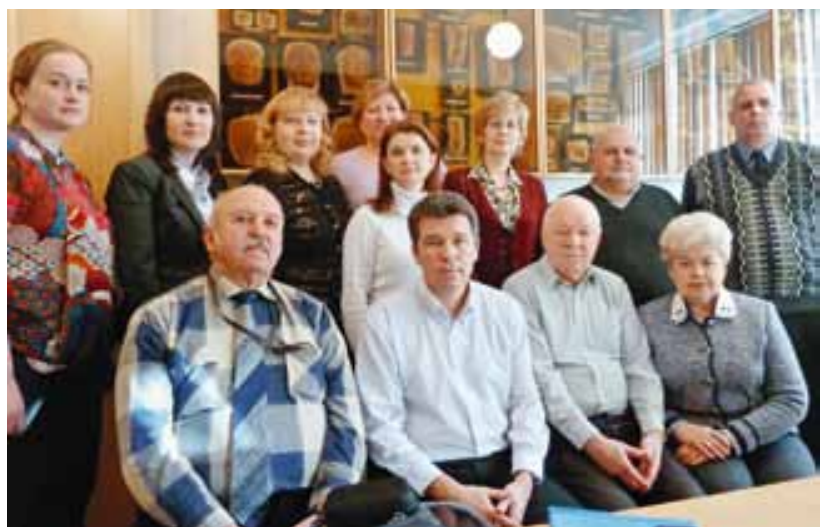

Действующий состав кафедры дерматовенерологии (2014 г.) 
Олег Раисович - член диссертационного совета ФГБУ «Уральский научно-исследовательский институт дерматовенерологии и иммунопатологии» Минздрава России (Екатеринбург), член правления Российского общества дерматовенерологов и косметологов и председатель Челябинского отделения Российского общества дерматовенерологов и косметологов имени И.И. Ильина. С 2011 г. возглавляет экспертную группу инфекционного направления областной аттестационной комиссии при Министерстве здравоохранения Челябинской области специалистов с высшим профессиональным образованием. С 2010 г. является секретарем областной межведомственной комиссии по проблемам социальной патологии при правительстве Челябинской области, в 2010 г. назначен главным врачом ГБУЗ «Челябинский областной клинический кожно-венерологический диспансер» и главным внештатным специалистом по дерматовенерологии и косметологии Министерства здравоохранения Челябинской области.

С 2011 г. количество сотрудников кафедры значительно увеличилось. Включив в свой состав кафедру кожных и венерических болезней Уральской государственной медицинской академии дополнительного образования и кафедру дерматологии и косметологии Челябинской государственной медицинской академии, O.P. Зиганшин возглавил коллектив, состоящий из шести докторов и пяти кандидатов медицинских наук. Существенно расширена материальная база кафедры, с ростом образовательных направлений увеличено количество учебных баз, которое к 2014 г. возросло до пяти. Обучение на кафедре ведется по 13 образовательным программам: для студентов пяти факультетов Южно-Уральского государственного медицинского университета, интернатура, ординатура по специальностям «дерматовенерология» и «косметология», профессиональная переподготовка, общее усовершенствование по специальности «дерматовенерология», профрессиональная переподготовка по специальности «косметология», тематические усовершенствования.

Основными направлениями научной работы сотрудников кафедры под руководством Олега Раисовича являются вопросы диагностики и лечения инфекций, передаваемых половым путем (ИППП), хронического простатита, эректильной дисфункции, мужского бесплодия, иммунология оппортунистических инфекций урогенитального тракта у женщин и мужчин, детская дерматология, исследования регуляции иммунитета в клинике кожных болезней, клинико-морфологических аспектов инъекционной косметологии, дерматоонкология.

Сотрудники кафедры активно участвуют в работе местных органов здравоохранения, являясь консультантами в лечебных учреждениях - учебных базах кафедры, членами комиссий по борьбе с ИППП, проводя конференции и заседания челябинского отделения Российского общества дерматовенерологов и косметологов имени И.И. Ильина, школы-семинары для врачей Челябинской области и Челябинска по различным вопросам дерматовенерологии и косметологии. 12 сентября 2014 года в честь юбилейной даты, в рамках научно-практической конференции дерматовнерологов и косметологов Челябинской области состоялась торжественная церемония открытия памятной мемориальной доски в честь выдающегося российского ученого-дерматовенеролога Иосифа Израилевича Ильина.

Несмотря на свое 70-летие или благодаря ему кафедра дерматовенерологии Южно-Уральского государственного медицинского университета молода и активна. Накопленный за годы работы опыт, сорормировавшийся у сотрудников с многолетним стажем, и инициативность молодых коллег, возглавляемых перспективным современным руководителем, позволяют коллективу успешно решать стоящие перед ним учебные и научные задачи. I

об авторах

О.Р. Зиганшин - д.м.Н., зав. кафедрой дерматовенерологии ГБОУ ВПО ЮУГМУ Минздрава России, Челябинск

О.В. Лысенко - д.м.н., профессор кафедры дерматовенерологии ГБОУ ВПО ЮУГМУ Минздрава России, Челябинск

Ю.Н. Ковалев - д.м.н., профессор, профессор кафедры дерматовенерологии ГБОУ ВПО ЮУГМУ Минздрава России, Челябинск

О.И. Летяева - к.м.Н., ассистент кафедры дерматовенерологии ГБОУ ВПО ЮУГМУ Минздрава России, Челябинск 